\title{
Seafloor Spreading and Mountain Building
}

CAN tectonic events on the continents be related to seafloor spreading several thousand kilometres away? The article by P. J. Coney on page 462 of this issue of Nature and that of R. W. R. Rutland in an earlier issue (Nature, 233, 252; 1971) relate mountain building episodes in North and South America to changing seafloor spreading in the Atlantic. The bordering areas, the Caribbean and Scotia Arc, have also been studied recently in the light of seafloor movements by G. L. Freeland and R. S. Dietz (Nature, 232, $20 ; 1971$ ) and by I. W. D. Dalziel and D. H. Elliot (Nature, 233, $246 ; 1971$ ). This sudden flurry of articles reflects how details of seafloor spreading are now becoming available so that it is possible to relate such distant events with each other.

Perhaps the chief reason why seafloor spreading was not considered seriously until the 1960 s was the apparent discrepancy between the essentially simple, localized pattern of spreading compared with the extensive, complicated patterns of mountain formation. The creation of new ocean floor takes place in an extremely narrow zone, possibly less than $30 \mathrm{~m}$ wide, at the centre of the ridge system, and this new oceanic lithosphere eventually descends back into the Earth's mantle at the oceanic trenches-again narrow zones compared with mountain systems of up to $1,000 \mathrm{~km}$ width. Between these two narrow active zones, the tectonic picture is quiescent; oceanic lithosphere is moving towards the trenches at different rates in different areas, although it is consistent over vast lithospheric plates on which only sedimentation is taking place, and the odd, persistent hot spot in the Earth's mantle is giving rise to a trail of volcanic islands. In contrast, mountain building occurs over wide regions of the continental crust with many phases of folding, faulting, igneous activity and metamorphism.

The discovery of major transform faults in the oceanic basins provided the first indisputable evidence of crustal movements of the magnitude required by the proponents of continental drift. On the whole, however, these faults could not be traced inland so that, for several years, it still seemed that there was little relation between the tectonics of the ocean floors and those of the continents. The establishment of plate tectonics indicated that there must be at least some broad correlation between these tectonically active areas although it still seemed improbable that detailed correlations would be made between changes in spreading rate and direction of the plates and the precise sequence of events in an orogenic system, even on the same plate.

It is, however, the simplicity and narrowness of the mechanism by which new ocean floor is added that are allowing determinations of detailed movements of the plates. If the creation ofseafloortook place over a wide region, many of these details would be lost in the "noise level" of the changing polarity of the Earth's magnetic field. These details, as they become available, are, however, becoming increasingly linked to specific changes in the degree of deformation, changes in the motion along faults, and so forth, within the orogenic systems of the continents. The current series of articles, such as that by Coney, mark only the start of this detailed correlation as they are based, so far, on magnetic records from those parts of the oceans which seem to reflect the simplest patterns, that is, where the locus of spreading has remained fixed, although the rate and direction of motion have changed. Coney is therefore able to distinguish three principal changes in spreading of the Atlantic plate from its initiation 150 to 180 million years ago, at 80,40 and 9 million years ago. This means that he is able to correlate, for example, the evolution of the Azores with the Laramide orogeny and so forth, with only slight reference to movements of the Pacific plate.

Areas, such as the Atlantic north of Ireland, will take longer to interpret as changes have also taken place in the position of the axis of spreading. Similarly, the discovery that not all plate motions are symmetric with respect to the oceanic ridges (J. K. Weissel and D. E. Hayes, Nature, 231, 518 ; 1971) must complicate the interpretation in some regions. Clearly, however, a synthesis of oceanic and orogenic motions on the Atlantic plates is becoming more feasible and, before long, the interaction between different plates will begin to emerge so that the tectonic activity will be seen in its true global perspective.

\section{Putling the Cerebellum to Sleep?}

ON page 481 of this issue of Nature, Siggins, Hoffer, Oliver and Bloom add another link to the growing chain of evidence which indicates that brain stem neurones rich in catecholamines are important regulators of activity levels in the cortices of the brain. They have demonstrated in rats that electrical stimulation in the neighbourhood of one such group of neurones leads to a prolonged inhibition of the impulse discharge from Purkinje cells-the output neurones of the cerebellar cortex. The aminerich neurones concerned are those of the locus coeruleus (LC) in the rostral part of the pons. That axons of LC neurones terminate in the cerebellar cortex was first shown using histochemical techniques but the work of Siggins et al. represents the first attempt to use neuro- physiological techniques to investigate the functioning of the pathway at the single neurone level. The potential importance of the path is emphasized by the finding that a single LC stimulus can produce a detectable decrease in the probability that individual Purkinje cells will discharge impulses; repetitive stimulation often leads to complete suppression of discharge.

It is difficult to speculate on the role of the projection in the normal operation of the cerebellar machinery. As Siggins et al. recognize, it has yet to be shown that the inhibition observed was directly mediated by synapses between the LC axons and the Purkinje cells. Such synapses have not been described but electron microscopical studies may yet help. At any event the long 